\title{
Preparation of Microcapsules Containing Phase Change Material and Silicon Carbide Powder with Interfacial Polycondensation Reaction Method
}

\author{
Ryo Morita, Natsukaze Saito, Yoshinari Taguchi, Masato Tanaka* \\ Graduate School of Science and Technology, Niigata University, Niigata, Japan \\ Email: ${ }^{*}$ tanaka@eng.niigata-u.ac.jp
}

Received 28 February 2015; accepted 21 March 2015; published 26 March 2015

Copyright $\odot 2015$ by authors and Scientific Research Publishing Inc.

This work is licensed under the Creative Commons Attribution International License (CC BY).

http://creativecommons.org/licenses/by/4.0/

(c) (i) Open Access

\section{Abstract}

The fundamental experiments were performed to establish the operational conditions required to prepare the microcapsules containing paraffin wax as a phase change material (PCM) and SiC powder with the interfacial polycondensation reaction. It was investigated how SiC powder affected a few characteristics of microcapsules such as the diameters of microcapsules, latent heat storage density, thermal responsibility and supercooling. In the experiment, the concentration of oil soluble surfactant, the revolution speed of impeller for preparing the $(0 / \mathrm{W})$ emulsion and the added weight of SiC powder were changed stepwise. The microcapsules containing PCM in which $\mathrm{SiC}$ powder was dispersed could be prepared well and characterized. The diameters of microcapsules increased by containing $\mathrm{SiC}$ powder and the content of $\mathrm{SiC}$ powder could be increased by performing surface modification of $\mathrm{SiC}$ powder. Latent heat storage density decreased with the content of SiC powder. Supercooling of PCM and thermal responsibility could be improved to some degree by containing SiC powder.

\section{Keywords}

PCM Microcapsule, Latent Heat Storage, Silicon Carbide, Interfacial Polycondensation Reaction, Paraffin Wax, Thermal Composite

\section{Introduction}

Hitherto, many kinds of microcapsules have been prepared and applied in the various fields such as thermal

\footnotetext{
${ }^{*}$ Corresponding author.
}

How to cite this paper: Morita, R., Saito, N., Taguchi, Y. and Tanaka, M. (2015) Preparation of Microcapsules Containing Phase Change Material and Silicon Carbide Powder with Interfacial Polycondensation Reaction Method. Materials Sciences and Applications, 6, 251-262. http://dx.doi.org/10.4236/msa.2015.63030 
energy storage, cosmetics, drugs, information recording materials, paintings and so on [1]-[4]. Among of these microcapsules, the microcapsules containing PCM have attracted great attention from industrial communities [5]-[8], because the microcapsules containing PCMs can absorb, store and release latent heat according to the PCM species and the amount of microencapsulated PCM [9]-[11].

The PCM microcapsules have been prepared by using suspension polymerization [12]-[14], in-situ polymerization [15] [16], interfacial polycondensation reaction [17]-[19] and miniemulsion polymerization [20] and applied in fabrics, building materials and automobile engine. The PCM microcapsules thus prepared are the fine particles with the core-shell structure which have the PCM core surrounded by a polymer shell. It is necessary that the polymer shell prevents PCM from leaking during the process of phase change and overcome mechanical stress. The bulky PCM is given the extremely large heat transfer area by being microencapsulated. However, supercooling is easy to occur due to the limited smaller hollow. Furthermore, the microcapsules made of a polymer shell and PCMs such as paraffin wax with low thermal conductivity have a less heat conductivity. However, it may be expected that these demerits could be improved by adding solid powder, which plays as a supercooling prevention agent and an improvement agent for heat conductivity. Namely, if solid powder with higher thermal conductivity could be dispersed in PCM, relative thermal conductivity of microcapsules could be improved. Also, if solid powder plays as a nucleating agent, super cooling could be prevented at the same time.

Thus, the microcapsules made of PCM and a filler with higher thermal conductivity, namely, the thermal composites may be prepared with the preparation methods stated above by adding solid powder into PCM. In these preparation processes, first, it is necessary to form the oil droplets (PCM-droplets) of PCM containing solid powder, namely, the stable (S/O)/W dispersion.

In general, the dispersing behaviour such as coalescence and break up of dispersed oil droplets are affected by containing solid powder in the oil droplets, because physical properties such as relative density and relative viscosity of oil phase are changed. In this case, the diameters of oil droplets are necessarily affected. In the case of preparing the microcapsules by using the $(\mathrm{S} / \mathrm{O}) / \mathrm{W}$ dispersion, the diameters of microcapsules are necessarily affected by solid powder in PCM.

So, it is important to investigate how solid powder dispersed in the PCM-droplets affects the dispersing behavior of the PCM-droplets in the turbulent field [21] [22]. However, there are no reports about the dispersing behaviors of PCM-droplets containing solid powder.

In this study, in order to investigate how solid powder affects the dispersing behavior of PCM-droplets and a few characteristics of PCM-microcapsules, it is tried to prepare the microcapsules containing PCM and SiC powder by the interfacial polycondensation reaction method. Here, $\mathrm{SiC}$ with higher thermal conductivity may be suitable to the improvement agent for PCM with lower thermal conductivity. The purposes of this study are to obtain the fundamental information about the dispersing behavior of PCM-droplets containing solid powder, to prepare the microcapsules containing PCM and SiC powder and to characterize the microcapsules.

\section{Experimental}

\subsection{Materials}

Materials used to prepare the microcapsules containing paraffin wax (PCM) and silicon carbide powder (SiC) were as follows.

Paraffin wax (Wako Pure Chemical Ind. Co., Ltd., Tokyo, Japan) with the melting point of $50^{\circ} \mathrm{C}$ was used as PCM. The oil soluble monomer and the water soluble monomer for the interfacial polycondensation reaction were toluen diisocyanate (TDI) and diethylene tetramine (DETA) (Wako Pure Chemical Ind. Co., Ltd, Tokyo, Japan), respectively. The continuous phase dissolving polyvinyl alcohol (PVA: Poly. Degree 500, Sapo. Degree 98 - 99) as a stabilizer was distilled water. Silicon carbide (SiC: thermal conductivity $3.5 \mathrm{w} / \mathrm{cm} / \mathrm{K}$ ) (Sunprite Ind. Co., Ltd., Tokyo, Japan) with the mean diameter of $0.5 \mu \mathrm{m}$ was added into PCM. Dehydrated toluen (Wako Pure Chemical Ind. Co., Ltd., Tokyo, Japan) was used as the solvent to modify the surface of silicon carbide by triethoxy vinylsilane (Shinetsu Chemical Co., Ltd., Tokyo, Japan).

\subsection{Surface Modification of Silicon Carbide}

Figure 1 shows the schematic diagram of experimental apparatus used to modifying SiC. The impeller with the diameter of $5.0 \mathrm{~cm}$ and the four baffles made of aluminium plate were set as shown in Figure 1. Dehydrate to- 
luene and triethoxyvinylsilane of the given volume and $\mathrm{SiC}$ of a given weight were added into the reactor of the separable flask with the effective volume of $500 \mathrm{~cm}^{3}$. The surface modification reaction was continued for $5 \mathrm{~h}$ at $109^{\circ} \mathrm{C}$. The modification conditions were shown in Table 1.

$\mathrm{SiC}$ modified thus was washed twice with ethanol, separated by filtration and then, dried at room temperature.

\subsection{Preparation of Microcapsules}

Figure 2 shows the schematic diagram of experimental apparatus for preparing the microcapsules. The reactor was set in the thermostatted water bath to keep the reaction temperature constant. The six bladed turbine impellers with the diameter of $5.0 \mathrm{~cm}$ were set at one third of liquid depth from the bottom. The four baffles made of aluminium plate were set to prevent air from entraining as shown in Figure 2.

Figure 3 shows the flow chart for preparing the microcapsules together with the microencapsulation mechanism of the model microcapsule tried to prepare. SiC and TDI were added into the melted PCM and stirred to prepare the $(\mathrm{S} / \mathrm{O})$ dispersion. The distilled water phase dissolving PVA was prepared as the continuous water phase. The (S/O) dispersion was added into the continuous water phase and stirred to form the $(\mathrm{S} / \mathrm{O}) / \mathrm{W}$ dispersion. After the dispersed oil droplets with the desired mean diameter were formed, the additive water phase dissolving DETA was poured into the $(\mathrm{S} / \mathrm{O}) / \mathrm{W}$ dispersion at the feeding velocity of $0.5 \mathrm{ml} / \mathrm{min}$ with the microcyringe and then, the interfacial polycondensation reaction was conducted for $24 \mathrm{~h}$ at $50^{\circ} \mathrm{C}$. The experimental conditions for preparing the microcapsules were shown in Table 2.

\subsection{Preparation of Microcapsules}

\subsubsection{Observation of Microcapsules}

The surface and inner structure of a microcapsule were observed by scanning electron microscope (JSM-5800: Nihon Denshi Co., Ltd., Tokyo, Japan). The whole of microcapsule was observed by stereo microscope (SE1145TR: Olympus Co., Ltd., Tokyo, Japan). SiC in the microcapsule was analyzed by electron probe microanalyzer (EPMA8705: Shimazu Seisakusho, Co., Ltd., Kyoto, Japan).

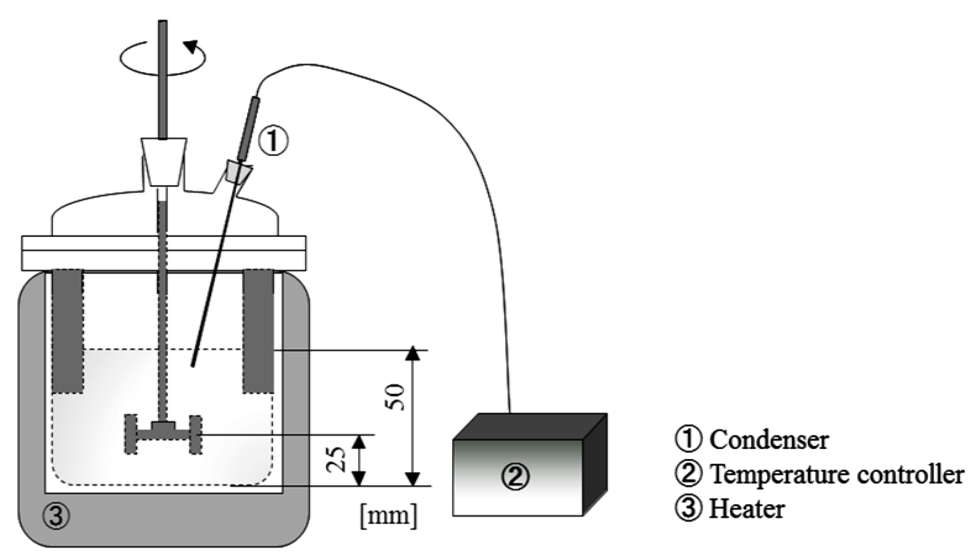

Figure 1. Schematic diagram of experimental apparatus for modifying SiC.

Table 1. Experimental conditions for surface modification.

\begin{tabular}{|c|c|}
\hline dehydrated toluen & 300 cc \\
\hline $\mathrm{SiC}$ & $10 \mathrm{~g}$ \\
\hline triethoxyvinylsilane & $0-0.75[\mathrm{~mol} / \mathrm{l}]$ \\
\hline reaction temperature & $109^{\circ} \mathrm{C}$ \\
\hline reaction time & $5 \mathrm{~h}$ \\
\hline revolution speed & 200 rpm \\
\hline
\end{tabular}




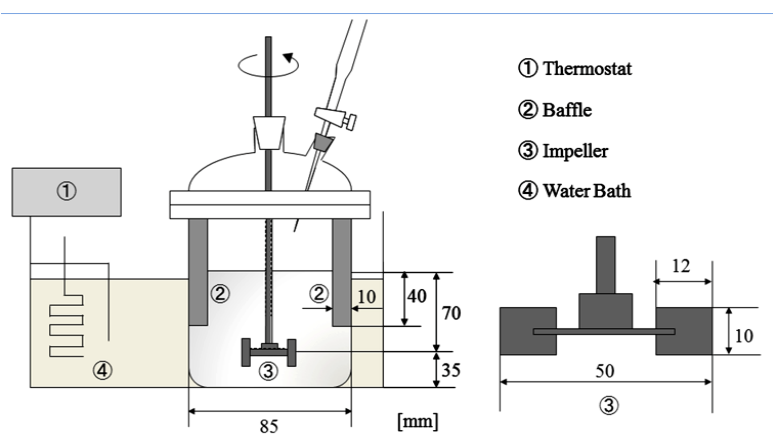

Figure 2. Schematic diagram of experimental apparatus for preparing microcapsules.

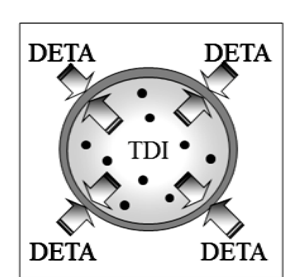

Interfacial Polycondensation

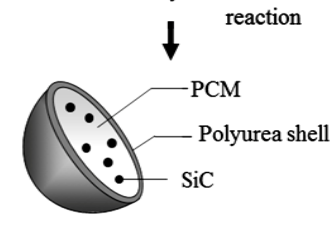

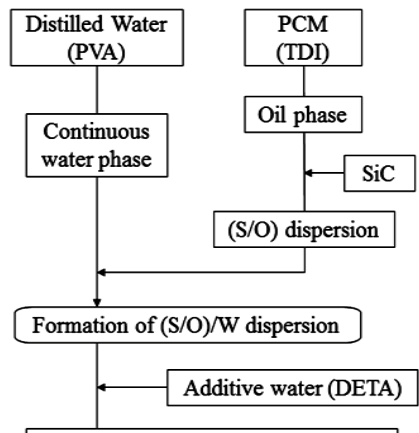

Interfacial Polycondensation reaction

Microcapsules

Figure 3. Flow chart for preparing microcapsules and microencapsulation mechanism.

Table 2. Experimental conditions for preparing microcapsules.

\begin{tabular}{cc}
\hline Continuous phase & $250 \mathrm{cC}$ \\
Distilled water & $\mathrm{CPVA}=0-1.0 \mathrm{wt} \%-\mathrm{H}_{2} \mathrm{O}$ \\
Stabilizer (PVA) & $10.0 \mathrm{~g}$ \\
Dispersed phase & $4.0 \mathrm{~g}\left(0.023 \mathrm{~mol}-\mathrm{H}_{2} \mathrm{O}\right)$ \\
PCM & $\mathrm{W}_{\mathrm{SiC}}=0-10 \mathrm{wt} \%-\mathrm{wax}$ \\
TDI & $30 \mathrm{cc}$ \\
SiC & $2.0 \mathrm{~g}\left(0.019 \mathrm{~mol}-\mathrm{H}_{2} \mathrm{O}\right)$ \\
Additive water phase & $0.5 \mathrm{cc} / \mathrm{min}$ \\
Distilled water & \\
DETA & $N_{r 1}=300-5000 \mathrm{rpm}$ \\
Feeding velocity & $\mathrm{t}=10 \mathrm{~min}$ \\
Preparation of (S/O)/W dispersion & $\mathrm{T}=50^{\circ} \mathrm{C}$ \\
Revolution speed & \\
Temperature & $N_{r 2}=150 \mathrm{rpm}$ \\
Polymerization process & $24 \mathrm{~h}$ \\
Revolution speed & $50^{\circ} \mathrm{C}$ \\
Revolution time & \\
Temperature & \\
\hline
\end{tabular}




\subsubsection{Diameter Distribution and Mean Diameter}

The diameter distributions and mean diameters of microcapsules were directly measured from the photographs of microcapsules taken by stereo microscope according to the method reported in the previous works [21] [22]. Here, the mean diameter was the Sauter mean diameter.

\subsubsection{Latent Heat Storage Density}

Latent heat storage density of PCM and microcapsule was measured by scanning differential calorimeter (DSC50: Shimazu Seisakusho, Co., Ltd., Kyoto, Japan).

\subsubsection{Content of $\mathrm{SiC}$}

The content of $\mathrm{SiC}$ microencapsulated was estimated from difference in the weight measured by thermogravimetry analyzer (DTG-50/50: Shimazu Seisakusho, Co., Ltd., Kyoto, Japan).

\section{Results and Discussion}

\subsection{Effects of Fundamental Experimental Conditions}

\subsubsection{Effects of PVA Concentration and Revolution Speed}

In order to investigate the effect of addition of SiC, first it may be necessary to prepare the microcapsule without $\mathrm{SiC}$ and to investigate the effects of fundamental background experimental conditions. So, the effects of both the PVA concentration and the revolution speed of impeller on a few characteristics of microcapsules such as the shape and the diameters were investigated without addition of SiC.

Figure 4 shows the optical microscopic photographs of microcapsules without $\mathrm{SiC}$ prepared by changing the PVA concentration ( $\mathrm{C}_{\mathrm{PVA}}$ ) at $N_{r}=300 \mathrm{rpm}$ (a) and by changing the revolution speed $\left(N_{r}\right)$ at $\mathrm{C}_{\mathrm{PVA}}=0.5 \mathrm{wt} \%$ (b). As the microcapsules prepared at $\mathrm{C}_{\mathrm{PVA}}=0 \mathrm{wt} \%$ were larger and irregular, the $(\mathrm{O} / \mathrm{W})$ emulsion was found to be unstable. However, with increasing the PVA concentration, the smaller spherical sound microcapsules could be prepared because of the formation of stable $(\mathrm{O} / \mathrm{W})$ emulsion. Also, the microcapsules could be prepared even by changing the revolution speed from $300 \mathrm{rpm}$ to $5000 \mathrm{rpm}$ and by forming the stable (O/W) emulsion. As these results are important to control the diameters of microcapsules, the effects of the PVA concentration and the revolution speed were investigated in detail as follows.

Figure 5 shows the dependence of mean diameters $\left(d_{p}\right)$ of microcapsules without SiC on the PVA concentration $\left(\mathrm{C}_{\mathrm{PVA}}\right)$ at $N_{r}=300 \mathrm{rpm}$ and the revolution speed $\left(N_{r}\right)$ at $\mathrm{C}_{\mathrm{PVA}}=0.5 \mathrm{wt} \%$. The mean diameters decreased from $520 \mu \mathrm{m}$ at $\mathrm{C}_{\mathrm{PVA}}=0.1 \mathrm{wt} \%$ to $13 \mu \mathrm{m}$ at $\mathrm{C}_{\mathrm{PVA}}=1.0 \mathrm{wt} \%$ with the PVA concentration, but abruptly increased at the PVA concentration smaller than $\mathrm{C}_{\mathrm{PVA}}=0.1 \mathrm{wt} \%$. Also, the mean diameters decreased from $320 \mu \mathrm{m}$ at $N_{r}=$ $300 \mathrm{rpm}$ to $8.24 \mu \mathrm{m}$ at $N_{r}=5000 \mathrm{rpm}$ with the revolution speed. These dependences of mean diameters on the

(a)
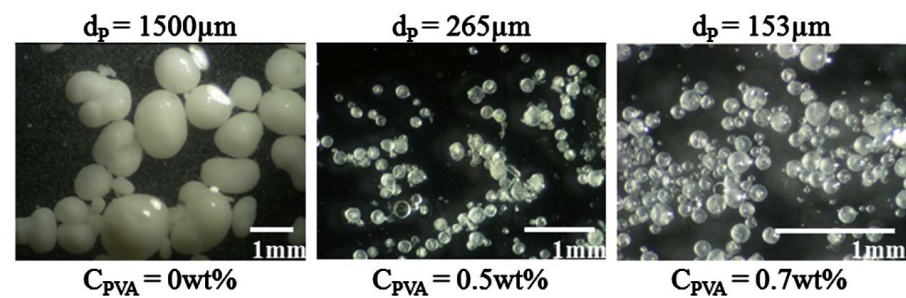

$d_{p}=265 \mu \mathrm{m}$

(b)

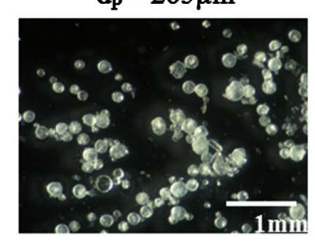

$$
\mathrm{N}_{\mathrm{r}}=300 \mathrm{rpm}
$$

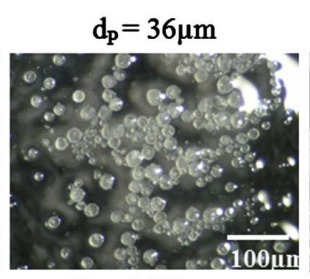

$\mathrm{N}_{\mathrm{r}}=1000 \mathrm{rpm}$
$\mathrm{d}_{\mathrm{P}}=7.2 \mu \mathrm{m}$

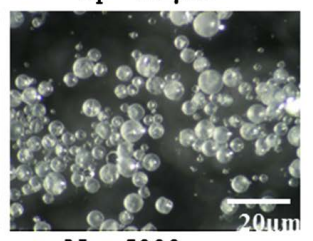

$\mathrm{N}_{\mathrm{r}}=5000 \mathrm{rpm}$

Figure 4. Photographs of microcapsules. (Effects of PVA concentration and revolution speed) (a) $N_{r}=300 \mathrm{rpm}$; (b) $\mathrm{C}_{\mathrm{PVA}}=0.5 \mathrm{wt} \%$. 


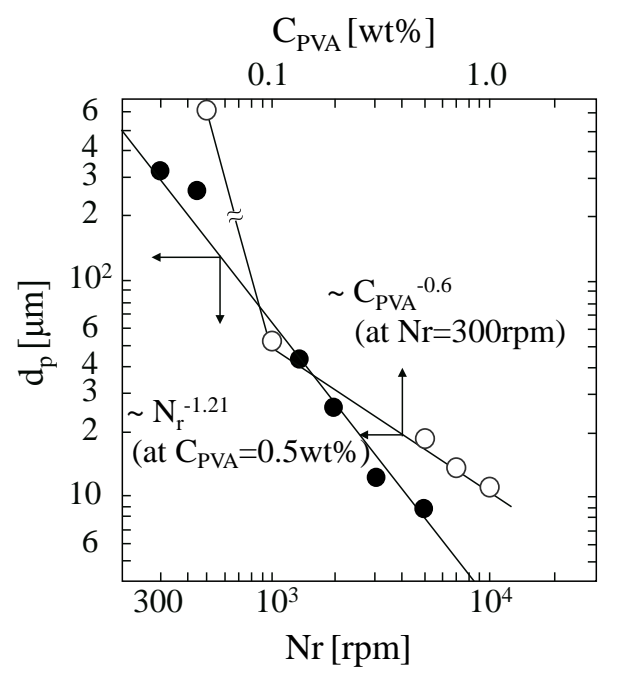

Figure 5. Dependence of mean diameter of microcapsules on PVA concentration and revolution speed.

PVA concentration and the revolution speed could be expressed by the following equation.

$$
d_{p} \sim N_{r}^{-1.21} C_{P V A}^{-0.60}\left(300 \mathrm{rpm} \leq N_{r} \leq 5000 \mathrm{rpm}, 0.1 \leq C_{P V A} \leq 1.0 \mathrm{wt} \%\right)
$$

In the interfacial polycondensation reaction method, the diameters of microcapsules almost become equal to those of the-PCM droplets or slightly larger than them.

The dependence of mean diameters of microcapsules on the revolution speed was found to coincide with that reported in the general oil-in-water emulsion, where the diameters of dispersed oil droplets were determined under breakup domain [23] [24]. Also, the dependence of mean diameters of dispersed oil droplets in the (O/W) emulsion on the stabilizer concentration was reported as $\mathrm{d}_{\mathrm{p}} \sim \mathrm{C}^{-0.3 \sim-1.0}$ [25]. It is well known that PVA molecules strongly adsorb on the interface between the oil phase and the water phase. Furthermore, on preparing the microcapsules with the interfacial poly condensation reaction method, the higher adsorption concentration of PVA prevents the microcapsule shell from forming, because the denser adsorption layer of PVA formed on the surface of droplets prevents the water soluble monomer and the oil soluble monomer from contacting and reacting at the interface.

Mizuno et al. reported that the growing velocity of the polyurea shell decreased with the PVA concentration [26].

Also, as the interfacial area per unit volume of reaction mixture should increase with decrease in the mean diameters of oil droplets, the concentrations of oil soluble monomer and water soluble monomer per unit interfacial area should decrease. As a result, the velocity of interfacial polycondensation reaction may decrease and the growing velocity of the shell thickness may become lower [26]. As it is possible that the shell thickness and the adsorption layer of PVA on the PCM-droplets affect the characteristics of microcapsules, it was investigated whether the PVA concentration affects the characteristics of microcapsules or not.

Figure 6 shows the effect of the PVA concentration on the phase change temperature (the melting start temperature $\left(T_{m}\right)$ and the solidifying temperature $\left(T_{s}\right)$ ) and latent heat storage density $(H)$. The melting start temperature and the solidifying temperature were not affected by the PVA concentration to the detectable degree at all. Also, latent heat storage density $(\mathrm{H})$ was not affected by the PVA concentration, too.

Taking the results obtained into consideration, the microcapsules were hereafter prepared at $\mathrm{C}_{\mathrm{PVA}}=0.5 \mathrm{wt} \%$ to investigate the addition of $\mathrm{SiC}$, because the spherical sound microcapsules could be prepared as shown in Figure 4.

\subsubsection{Effect of Addition of $\mathrm{SiC}$}

The effect of addition of $\mathrm{SiC}$ on a few characteristics of microcapsules was investigated on the basis of results obtained above.

Figure 7 shows the optical microscopic photographs of microcapsules without and with $\mathrm{SiC}$ under the condi- 


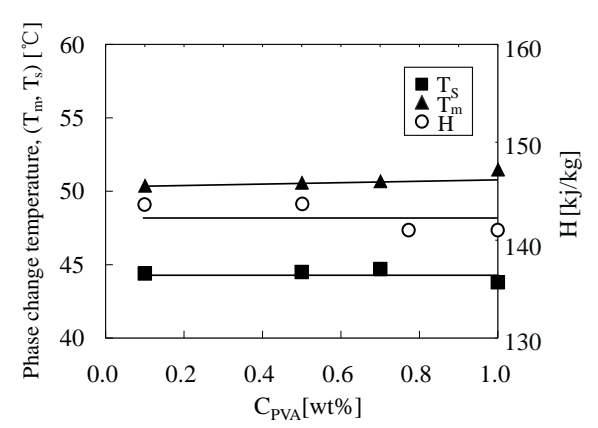

Figure 6. Effect of PVA concentration on phase change temperature and latent heat storage density.

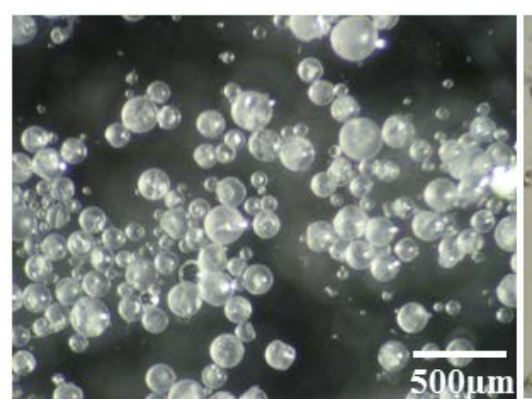

(a)

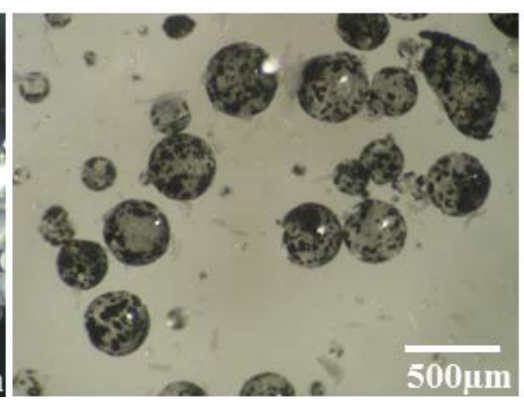

(b)

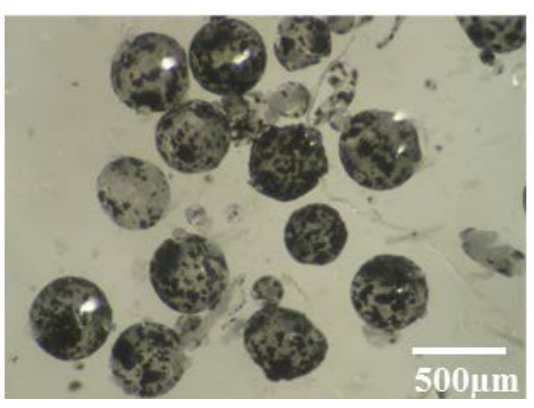

(c)

Figure 7. Optical microscopic photographs of microcapsules without and with SiC. (a) $\mathrm{W}_{\mathrm{SiC}}=0 \mathrm{wt} \%$-wax; (b) $\mathrm{W}_{\mathrm{SiC}}=3 \mathrm{wt} \%$ wax; (c) $\mathrm{W}_{\mathrm{SiC}}=10 \mathrm{wt} \%-w a x ;\left(N_{r}=500 \mathrm{rpm}, \mathrm{C}_{\mathrm{PVA}}=0.5 \mathrm{wt} \%\right)$.

tions of $N_{r}=500 \mathrm{rpm}$ and $\mathrm{C}_{\mathrm{PVA}}=0.5 \mathrm{wt} \%$. From these photographs, $\mathrm{SiC}$ contained in the microcapsules could be observed, but $\mathrm{SiC}$ coagulated in the microcapsules. Furthermore, the microcapsules containing less $\mathrm{SiC}$ were observed, because $\mathrm{SiC}$ may break away from the PCM-droplets during the microencapsulation process.

Also, Figure 8 shows the diameter distributions (a) of microcapsules without and with $\mathrm{SiC}$ at $N_{r}=500 \mathrm{rpm}$ and $N_{r}=5000 \mathrm{rpm}$ and the optical microscopic photographs of microcapsules with $\mathrm{SiC}$ at $N_{r}=500 \mathrm{rpm}$ and $N_{r}=$ 5000 rpm (b).

From Figure 8(a), it is found that the diameter distributions shifted to the larger diameter side due to addition of SiC. Also, from Figure 8(b), it is found that $\mathrm{SiC}$ was contained well in the microcapsules even changing the revolution speed. The diameters of oil droplets containing solid powder may become larger because of increase both in the relative viscosity of oil droplet phase and in the viscous force against destructive force in the turbulent field [23] [24]. Accordingly, the diameters of microcapsules containing SiC may become larger. As it is possible that the amount of contained $\mathrm{SiC}$ affects a few characteristics such as the diameter and latent heat storage density of microcapsules, the effect of addition of $\mathrm{SiC}$ was investigated in detail.

Figure 9 shows the dependence of mean diameters of microcapsules on the revolution speed $\left(N_{r}\right)$ at $\mathrm{W}_{\mathrm{SiC}}=0$ and $3.0 \mathrm{wt} \%$ and the added weight of $\mathrm{SiC}\left(\mathrm{W}_{\mathrm{SiC}}\right)$ at $N_{r}=500 \mathrm{rpm}$. The mean diameters decreased with the revolution speed, become larger than those of microcapsules without $\mathrm{SiC}$ and increased with the added weight of $\mathrm{SiC}$, respectively. These dependencies are expressed as the following Equation (2).

$$
d_{p} \sim N_{r}^{-1.21} W_{\text {Sic }}^{0.68}
$$

The dependence $\left(N_{r}^{-1.21}\right)$ (as shown in Figure 5) of mean diameters of the microcapsules without SiC on the revolution speed becomes equal to that $\left(N_{r}^{-1.21}\right)$ for the microcapsules with SiC. From these results, it is found that the PCM-droplets without and with $\mathrm{SiC}$ were formed under breakup domain. Thus, the correlating equations as Equations (1) and (2) are valuable to control the diameters of microcapsules without and with SiC.

\subsubsection{Effect of Surface Modification}

As the microcapsules containing less $\mathrm{SiC}$ were observed in Figure 7, the effect of surface modification of SiC 

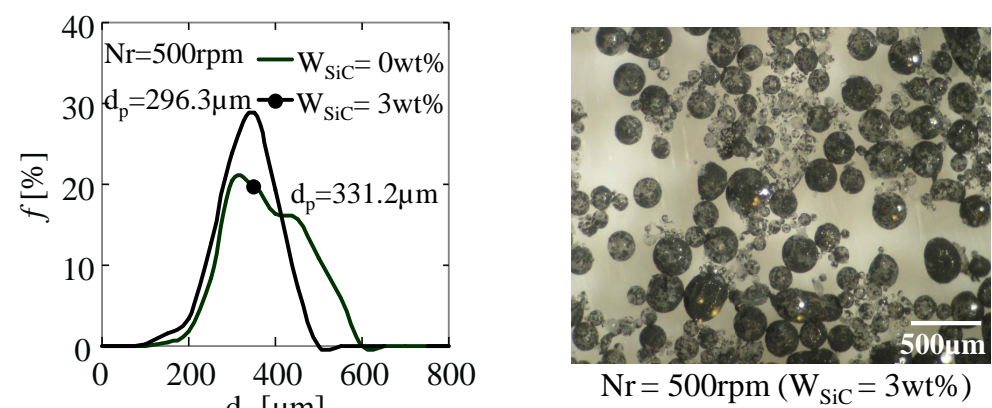

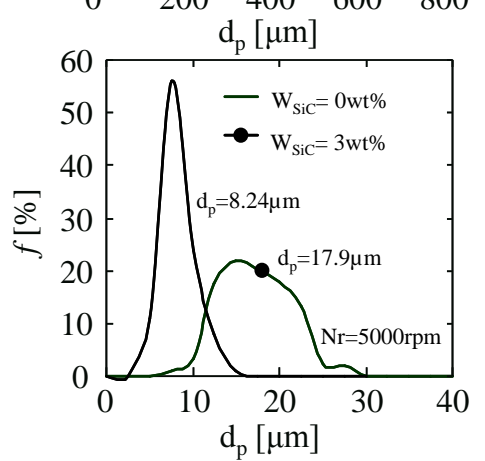

(a)

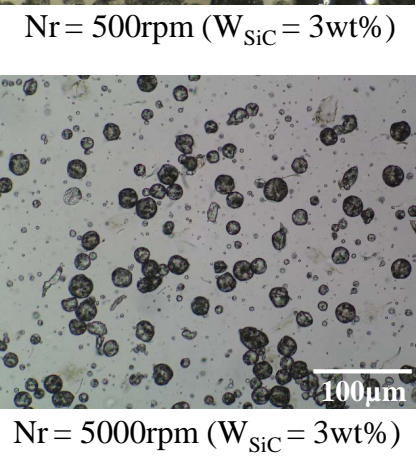

(b)

Figure 8. Diameter distributions and optical microscopic photographs.

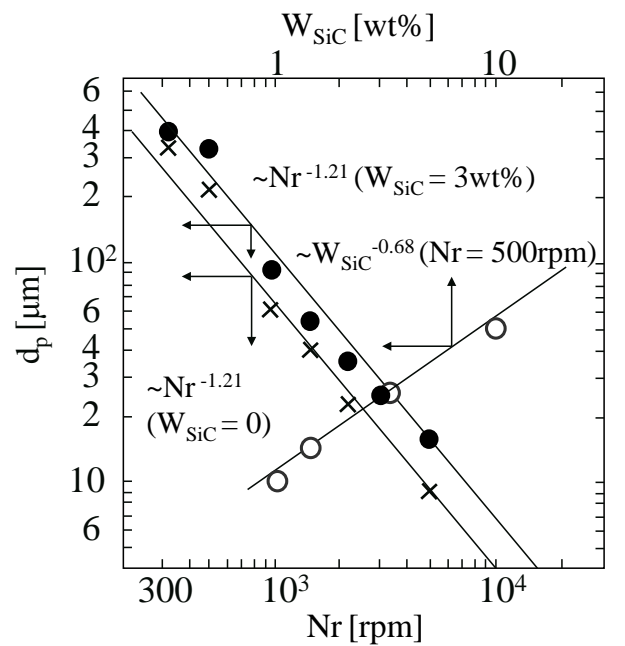

Figure 9. Dependence of mean diameters on revolution speed and added weight of SiC.

on the content and the dispersing feature of $\mathrm{SiC}$ in the microcapsule were investigated.

Figure 10 shows the dependence of mean diameters of microcapsules on the concentration $\left(\mathrm{C}_{\mathrm{s}}\right)$ of surface modification agent. It is found that the mean diameters increased with the concentration of surface modification agent. This result may be due to increase in the content of SiC and the relative viscosity of oil droplets as stated above.

Figure 11 shows the effect of surface modification on the content, where the measured contents (W'siC) are compared with those $\left(\mathrm{W}_{\mathrm{SiC}}\right)$ based on the feed. It is found that the measured contents ( $\left.\mathrm{W}^{\prime}{ }_{\mathrm{SiC}}\right)$ for modified SiC were larger than those for unmodified $\mathrm{SiC}$ and become close to the contents $\left(\mathrm{W}_{\mathrm{SiC}}\right)$ based on the feed. This result may be due to increase in the hydrophobicity of the surface of SiC and affinity of SiC to PCM.

Figure 12 shows the SEM photographs (A, B) and the X-ray images (C, D) of microcapsules prepared by changing the added weight of unmodified SiC. From Figure 12, it is found that the microcapsules without and 


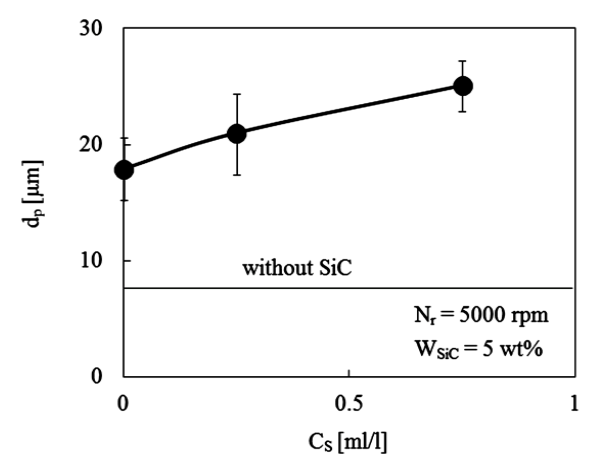

Figure 10. Dependence of mean diameter on concentration of modification agent.

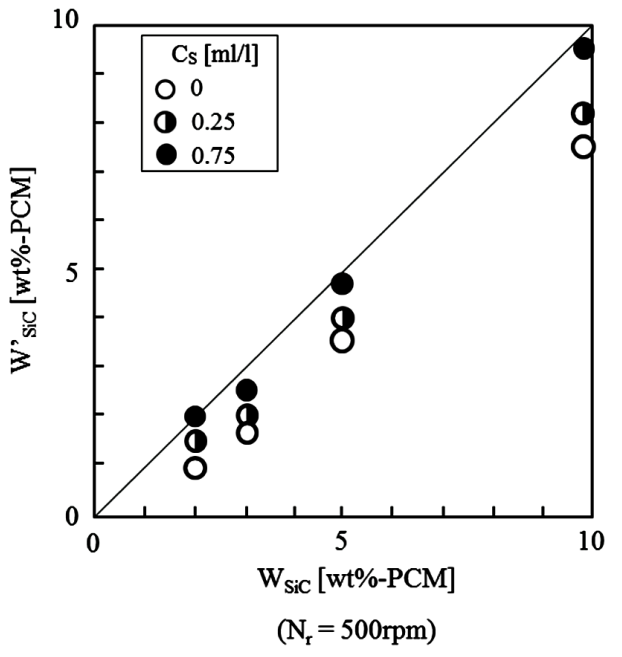

Figure 11. Effect of modification on content.

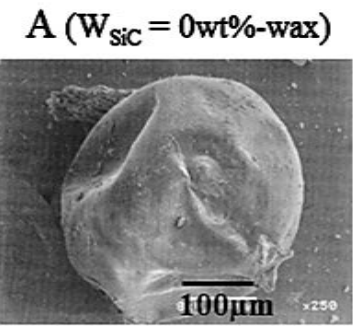

(a) Microcapsule

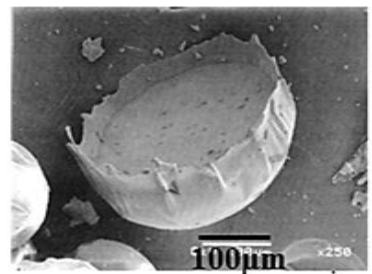

(b) Cross Section

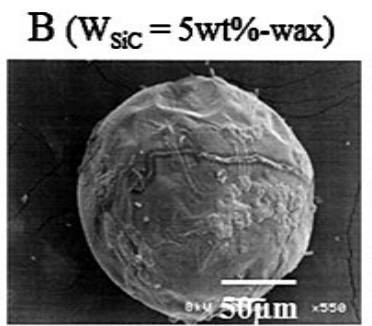

(a) Microcapsule

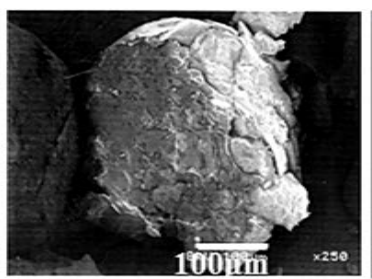

(b) Cross Section

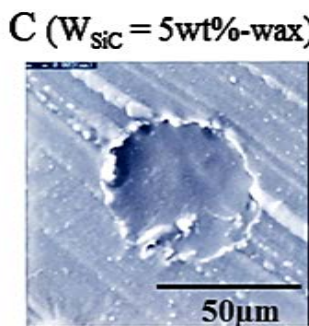

(a) Secondary Electron Image

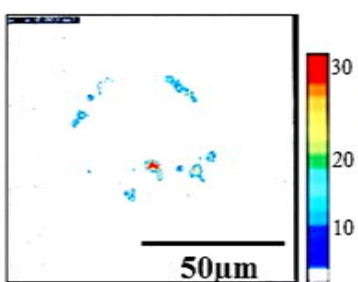

(b) $x$-ray image

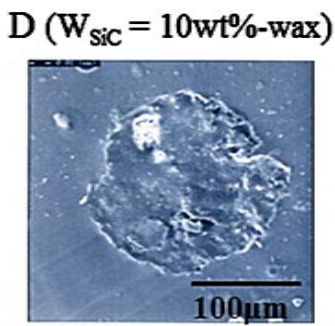

(a) Secondary Electron Image

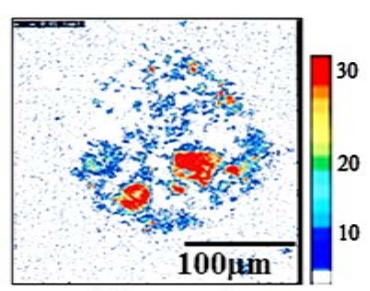

(b) $\mathrm{x}$-ray image

$$
\left(\mathrm{N}_{\mathrm{r}}=500 \mathrm{rpm}\right)
$$

Figure 12. SEM photographs and x-ray images (with unmodified SiC). 
with $\mathrm{SiC}$ were spherical $[\mathrm{A}(\mathrm{a}), \mathrm{B}(\mathrm{a})]$ and the amount of $\mathrm{SiC}$ contained in the microcapsule could be increased by increasing the added weight of $\mathrm{SiC}[\mathrm{C}(\mathrm{b}) \mathrm{D}(\mathrm{b})]$.

Figure 13 shows the effect of surface modification of $\mathrm{SiC}$ on the dispersing feature of $\mathrm{SiC}$ in the microcapsule. The unmodified SiC dispersed in the circumferential region of microcapsule, however, the modified SiC dispersed in the whole region of microcapsule. This may be due to increase in both hydrophobicity of surface and the stability of SiC. As a result, the content could be increased due to surface modification as shown in Figure 10 and Figure 11.

\subsection{Effect of SiC on Thermal Characteristics}

Figure 14 shows the DSC curves of PCM (a) and microcapsules with SiC $\left(\mathrm{W}_{\mathrm{SiC}}=3 \mathrm{wt} \%\right)$ (b). The endothermic peaks of PCM and microcapsules do not equal to the exothermic peaks of them because of supercooling and the reaction remainder such as DETA. Furthermore, the endothermic and the exothermic peaks of PCM were merely smaller than those of microcapsules because of the reaction remainder such as DETA, the microcapsule shell and SiC. Meanwhile, latent heat storage density of microcapsule was smaller than that of PCM because of increase in the weight of microcapsules due to the shell and SiC contained.

Figure 15 shows the effect of $\mathrm{SiC}$ on latent heat storage density (a) and the phase change temperature (b).

unmodified SiC

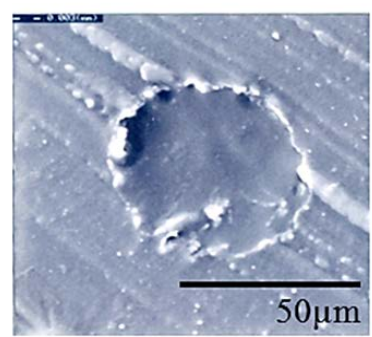

(a) Secondary Electron Image

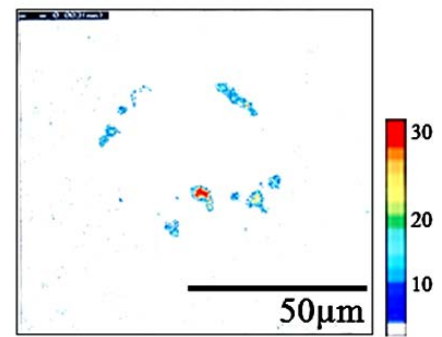

(b) x-ray Image

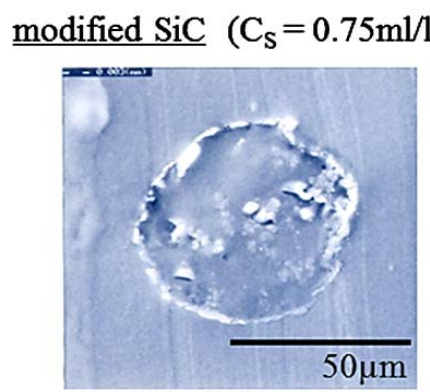

(a) Secondary Electron Image

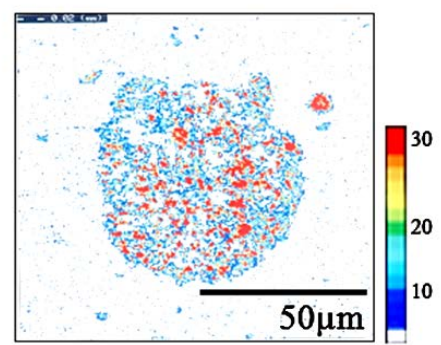

(b) x-ray Image

$$
\left(\mathrm{W}_{\mathrm{SiC}}=5 \mathrm{wt} \% \text {-wax, } \mathrm{N}_{\mathrm{r}}=500 \mathrm{rpm}\right)
$$

Figure 13. Effect of surface modification.

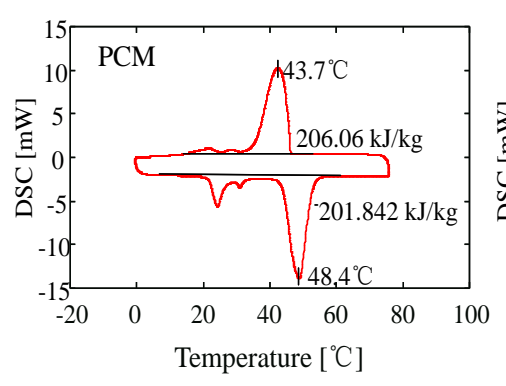

(a)

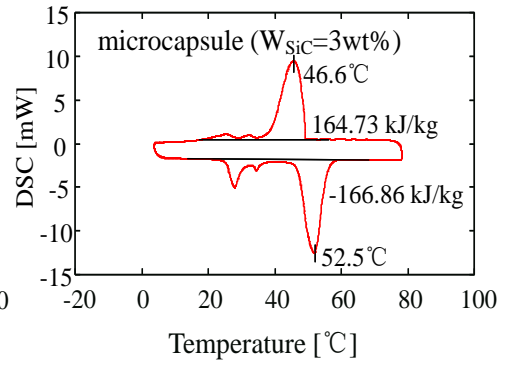

(b)

Figure 14. DSC curves of PCM and microcapsules with SiC. 


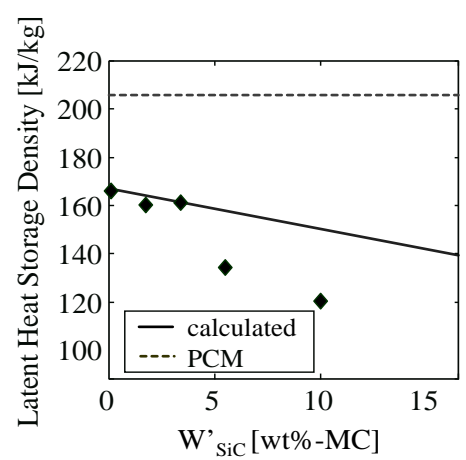

(a)

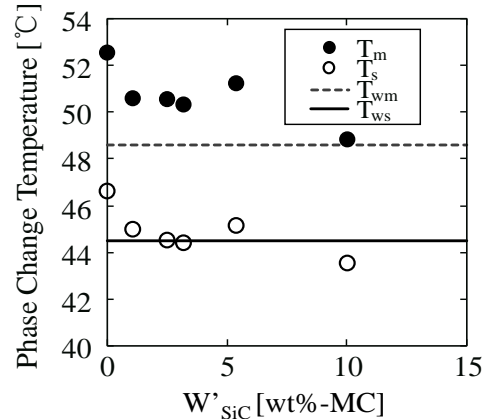

(b)

Figure 15. Effect of $\mathrm{SiC}$ on latent heat storage density and phase change temperature.

From Figure 15(a), the following results were obtained. Namely, latent heat storage density calculated on the basis of the PCM amount in the feed is very smaller than that of PCM. Furthermore, latent heat storage density of microcapsules without $\mathrm{SiC}$ and with $\mathrm{SiC}$ of $2 \mathrm{wt} \%$ and $3 \mathrm{wt} \%$ become equal to the calculated values, but latent heat storage density of microcapsules with $\mathrm{SiC}$ of $5 \mathrm{wt} \%$ and $10 \mathrm{wt} \%$ become smaller than the caluculated values.

Also, the reason why the measured values are smaller than the calculated values may be due to the lower content, because PCM should leak during the microencapsulation process.

On the other hand, from Figure 15(b), the following valuable results could be obtained. The melting start temperature $\left(T_{m}\right)$ and the solidifying temperature $\left(T_{s}\right)$ at $W_{\mathrm{Sic}}^{\prime}=0$ become higher than those $\left(T_{\mathrm{Wm}}, \mathrm{T}_{\mathrm{Ws}}\right)$ of PCM. This result may be due to supercooling in the limited smaller hollow of the microcapsules and lower thermal conductivity. However, with increasing $\mathrm{W}_{\mathrm{SiC}}^{\prime}$ the melting start temperature $\left(\mathrm{T}_{\mathrm{m}}\right)$ and the solidifying temperature $\left(\mathrm{T}_{\mathrm{s}}\right)$ gradualy become close to those $\left(\mathrm{T}_{\mathrm{Wm}}, \mathrm{T}_{\mathrm{Ws}}\right.$ ) of PCM (especially to $\mathrm{T}_{\mathrm{Ws}}$ at $\mathrm{W}_{\mathrm{SiC}}^{\prime}=1 \mathrm{wt} \%$ ).

From these results, it may be expected that $\mathrm{SiC}$ contained should play as a supercooling prevention agent and improvement agent for thermal conductivity of the microcapsules. Although the thermal characteristics of microcapsules can be improved by microencapsulating $\mathrm{SiC}$ at the same time, however, latent heat storage density decrease. For example, at $\mathrm{W}_{\mathrm{SiC}}^{\prime}=10 \mathrm{wt} \%$, latent heat storage density decreases from $165 \mathrm{~kJ} / \mathrm{kg}$ of PCM to 120 $\mathrm{kJ} / \mathrm{kg}$. For overcoming these demerits, it is necessary to increase the content of PCM and to select a filler with smaller density and higher thermal conductivity.

\section{Conclusions}

It was tried to prepare the microcapsules containing paraffin wax as PCM and SiC with the interfacial polycondensation reaction method and to characterize. The following fundamental valuable results could be obtained.

1) The diameters of microcapsules without and with $\mathrm{SiC}$ were determined under break up domain in the turbulent field.

2) The microcapsules containing paraffin wax and SiC could be prepared well.

3) The diameter of microcapsules increased with the weight of SiC contained.

4) The content of $\mathrm{SiC}$ could be increased by modifining $\mathrm{SiC}$ because of increase in hydrophobicity and affinity of SiC to PCM.

5) Thermal conductivity in the microcapsule could be improved by microencapsulating $\mathrm{SiC}$ at the same time.

6) $\mathrm{SiC}$ played a supercooling prevention agent in the microcapsules.

\section{References}

[1] Kondo, T. and Tanaka, M. (1975) Microcapsules (Preparation, Properties, Application). Sankyo Shuppan, Tokyo.

[2] Kondo, T. (1967) Saishin Maikurokapseruka Gijutsu (Microencapsulation Technique). TES, Tokyo.

[3] Tanaka, M. (2008) Key Point of Preparation of Nano/Microcapsules. Techno System Publishing Co. Ltd., Tokyo.

[4] Koishi, M., Eto, K. and Higure, H. (2005) (Preparation + Utilization) Microcapsules. Kogyo Chosakai, Tokyo. 
[5] Yamagishi, Y., Sugeno, T., Takeuchi, H. and Pyatenko, A.T. (1998) Themal Characteristics of Supercooles Phase Change Materials inside Microcapsules. Netsu Bussel, 12, 10-17. http://dx.doi.org/10.2963/jitp.12.10

[6] Yamagishi, Y., Sugeno, T., Takeuchi, H. and Pyatenko, A.T. (1998) Forced Convection Heat Transfer with Microencapsulated Phase-Change-Material Slurries. Kagaku Kogaku Ronbunshu, 24, 104-110. http://dx.doi.org/10.1252/kakoronbunshu.24.104

[7] Yamagishi, Y., Takeuchi, H. and Pyatenko, A.T. (1999) Pyatenko, Characteristics of Microencapsulated PCM Slurry as a Heat-Transfer Fluid. AIChE Journal, 45, 696-707. http://dx.doi.org/10.1002/aic.690450405

[8] Stritih, U. and Novak, P. (1996) Solar Heat Storage Wall for Building Ventilation. Renewable Energy, 8, $268-271$. http://dx.doi.org/10.1016/0960-1481(96)88860-4

[9] Zhaoa, C.Y. and Zhang, G.H. (2011) Review on Microencapsulated Phase Change Materials (MEPCMs): Fabrication, Characterization and Applications. Renewable and Sustainable Energy Reviews, 15, 3813-3832. http://dx.doi.org/10.1016/j.rser.2011.07.019

[10] Yuan, Y., Zhang, N., Tao, W., Cao, X. and He, Y. (2014) Fatty Acids as Phase Change Materials: A Review. Renewable and Sustainable Energy Reviews, 29, 482-498. http://dx.doi.org/10.1016/j.rser.2013.08.107

[11] Jamekhorshid, A., Sadrameli, S.M. and Farid, M. (2014) A Review of Microencapsulation Methods of Phase Change Materials (PCMs) as a Thermal Energy Storage (TES) Medium. Renewable and Sustainable Energy Reviews, 31, 531542. http://dx.doi.org/10.1016/j.rser.2013.12.033

[12] Zhang, X.X., Tao, X., Yick, K.I. and Wang, X.C. (2004) Structure and Thermal Stability of Microencapsulated Phase-Change Materials. Colloid and Polymer Science, 282, 330-336. http://dx.doi.org/10.1007/s00396-003-0925-y

[13] Tang, X., Li, W., Shi, H., Wang, X., Wang, J. and Zhang, X. (2013) Fabrication, Characterization, and Supercooling Suppression of Nanoencapsulated n-Octadecane with Methyl Methacrylate-Octadecyl Methacrylate Copolymer Shell. Colloid and Polymer Science, 291, 1705-1712. http://dx.doi.org/10.1007/s00396-013-2905-1

[14] Sánchez, L., Sánchez, P., Carmona, M., Lucas, A. and Rodríguez, J.F. (2008) Influence of Operation Conditions on the Microencapsulation of PCMs by Means of Suspension-Like Polymerization. Colloid and Polymer Science, 286, 10191027. http://dx.doi.org/10.1007/s00396-008-1864-4

[15] Su, J., Ren, L. and Wang, L. (2005) Preparation and Mechanical Properties of Thermal Energy Storage Microcapsules. Colloid and Polymer Science, 284, 224-228. http://dx.doi.org/10.1007/s00396-005-1368-4

[16] Su, J.F., Wang, S.B., Zhang, Y.Y. and Huang, Z. (2011) Physicochemical Properties and Mechanical Characters of Methanol-Modified Melamine-Formaldehyde (MMF) Shell microPCMs Containing Paraffin. Colloid and Polymer Science, 289, 111-119. http://dx.doi.org/10.1007/s00396-010-2328-1

[17] Cho, J.S., Kwon, A. and Cho, C.G. (2002) Microencapsulation of Octadecane as a Phase-Change Material by Interfacial Polymerization in an Emulsion System. Colloid and Polymer Science, 280, 260-266. http://dx.doi.org/10.1007/s00396-001-0603-X

[18] Cheng, F., Wei, Y., Zhang, Y., Wang, F., Shen, T. and Zong, C. (2013) Preparation and Characterization of PhaseChange Material Nanocapsules with Amphiphilic Polyurethane Synthesized by 3-allyloxy-1,2-propanediol. Journal of Applied Polymer Science, 130, 1879-1889. http://dx.doi.org/10.1002/app.39302

[19] Borreguero, A.M., Rodríguez, J.F., Valverde, J.L., Peijs, T. and Carmona, M. (2013) Characterization of Rigid Polyurethane Foams Containing Microencapsulted Phase Change Materials: Microcapsules Type Effect. Journal of Applied Polymer Science, 128, 582-590. http://dx.doi.org/10.1002/app.38226

[20] Cortazar, M.G. and Rodríguez, R. (2013) Thermal Storage Nanocapsules by Miniemulsion Polymerization. Journal of Applied Polymer Science, 127, 5059-5064. http://dx.doi.org/10.1002/app.38124

[21] Tanaka, M., Nakata, K. and Oyama, Y. (1970) Coalescence of Dispersed Liquid Droplets in a Batch Type of Stirred Tank Reactor. Kagaku Kogaku, 34, 893-897. http://dx.doi.org/10.1252/kakoronbunshu1953.34.893

[22] O’shima, E. and Tanaka, M. (1982) Coalescence and Breakup of Droplets in Suspension Polymerization of Styrene. Kagaku Kogaku Ronbunshu, 8, 86-90. http://dx.doi.org/10.1252/kakoronbunshu.8.86

[23] Tanaka, M. (1985) Local Droplet Diameter Variation in a Stirred Tank. Canadian Journal of Chemical Engineering, 63, 723-727. http://dx.doi.org/10.1002/cjce.5450630504

[24] Tanaka, M. and O’Shima, E. (1988) Dispersing Behaviour of Droplets in Suspension Polymerization of Styrene in a Loop Reactor. The Canadian Journal of Chemical Engineering, 66, 29-35. http://dx.doi.org/10.1002/cjce.5450660104

[25] Yuan, H.G., Kalfas, G. and Ray, W.H. (1991) Suspension Polymerization. Journal of Macromolecular Science, Part C, 31, 215-299. http://dx.doi.org/10.1080/15321799108021924

[26] Mizuno, K., Taguchi, Y. and Tanaka, M. (2005) The Effect of the Surfactant Adsorption Layer on the Growth Rate of the Polyurethane Capsule Shell. Journal of Chemical Engineering of Japan, 38, 45-48. http://dx.doi.org/10.1252/jcej.38.45 